\title{
Principal Quality and Student Attendance
}

\author{
Brendan Bartanen ${ }^{1}$
}

Student attendance is increasingly recognized as an important measure of educational success, which has spurred a body of research examining the extent to which schools can affect this outcome. However, prior work almost exclusively focuses on teachers, and no studies have explicitly examined the importance of school leaders. This study begins to fill this gap by estimating principal value-added to student absences. Drawing on statewide data from Tennessee over a decade, I find that principal effects on student absences are comparable in magnitude to effects on student achievement. Moving from the 25th to 75th percentile in principal value-added decreases student absences by 1.4 instructional days and lowers the probability of chronic absenteeism by 4 percentage points. Principals have larger effects in urban and high-poverty schools, which also have the highest baseline absenteeism rates. Finally, principals who excel at decreasing student absences may not be those who excel at increasing student test scores, and high-stakes accountability measures, such as supervisor ratings, fail to identify principals who decrease student absenteeism.

Keywords: econometric analysis; economics of education; educational policy; principals; regression analyses; research methodology

olicymakers are increasingly focused on lowering rates of student absenteeism. Recent reports found that approximately $15 \%$ of students are "chronically absent" each year, which is typically defined as missing $10 \%$ or more of the instructional days in a school year (Jordan et al., 2018). Increased attention to absences is exemplified by recent reforms in the Every Student Succeeds Act (ESSA), which requires states to include chronic absenteeism rates as part of their report cards to the federal government. Additionally, as part of the ESSA reform that requires states to include in their accountability plan at least one indicator of school quality or student success that does not involve state test scores or graduation rates (commonly referred to as the "fifth indicator" ), 36 states have included an indicator related to student attendance (Jordan \& Miller, 2017).

Undoubtedly, the federal requirement to track and report these outcomes explains the choice by many states to focus on attendance, whereas other potential indicators (e.g., school climate or students' social-emotional skills) require capacity and resources to design new measures and implement them across the state. Nevertheless, a large body of evidence highlights that reducing absenteeism is a worthy target for school improvement efforts. For instance, several prior studies established a credible causal link between student absenteeism and lower academic achievement (Aucejo \& Romano, 2016; Gershenson et al., 2017; Goodman, 2014; Gottfried, 2009, 2010; Liu et al., 2019). Further, Liu et al. (2019) showed that beyond lowering test scores, high school absences decrease the probability of on-time high school graduation and immediate college enrollment. Additional correlational evidence suggests that absences may lead to increased alcohol/drug use (Hallfors et al., 2002; Henry $\&$ Thornberry, 2010) and lower likelihood of future employment (Cattan et al., 2017). Student attendance is also a common proxy measure for character skills (e.g., conscientiousness), which are valued by employers in the labor market (Heckman \& Kautz, 2013).

Increased attention to student absenteeism has spurred exploration of the extent to which schools affect this outcome, though existing work largely focused on teachers. For instance, recent research demonstrated that teachers have substantial effects on students' non-test score outcomes, including absences (Backes \& Hansen, 2018; Gershenson, 2016; Jackson, 2018; Liu \& Loeb, 2019). ${ }^{2}$ These effects are comparable to, if not larger than, teachers' effects on test scores, and teachers who excel at raising

\footnotetext{
${ }^{1}$ Texas A\&M University, College Station, TX
} 
test scores are not the same teachers who excel at decreasing absences, on average.

Drawing on 11 years of statewide data from Tennessee, this study contributes to the literature by examining whether principals affect student absences using a value-added (VA) framework. A large body of research linked effective leadership to school performance, including higher student test scores (Branch et al., 2012; Chiang et al., 2016; Coelli \& Green, 2012; Dhuey \& Smith, 2014, 2018; Grissom et al., 2015), better school climate (Burkhauser, 2017; Kraft et al., 2016; Sebastian \& Allensworth, 2012), and lower teacher turnover (Boyd et al., 2011; Grissom \& Bartanen, 2019b; Ladd, 2011). To date, however, no studies have estimated principal effects on student absenteeism. To help fill this gap, I answer the following research questions:

Research Question 1: What effect do principals have on student absences?

Research Question 2: How does the magnitude of principal effects on absences vary by school context?

Research Question 3: To what extent are estimates of principals' effects on absences correlated with other measures of principal effectiveness, including principal effects on achievement and rubric-based ratings from supervisors?

Isolating the effects of individual principals on student absences presents a formidable empirical challenge. Consistent with approaches used in prior work to estimate principal effects on student achievement, I employ VA models with both principal and school fixed effects to isolate the impact of principal quality from other factors - such as the neighborhood or the quality of the school building-that might affect student absenteeism but that the principal cannot control. However, drawing from the teacher effects literature, I also implement a modified version of the drift-adjusted VA estimator proposed by Chetty et al. (2014). This approach, which has not been applied in the principal effects literature, relaxes the assumption that principal quality is fixed over time.

The next section presents a framework connecting principal quality and student absenteeism. I then discuss the challenges of estimating principal effects on student outcomes as well as the approaches pursued in prior studies. Next, I describe the data and methods used to produce estimates of principals' effects on student absences, including the implementation of the driftadjusted VA estimator. I then present the results. The concluding section discusses implications for policy and research, limitations, and avenues for future work.

\section{The Role of Principals in Improving Student Attendance}

While this study is the first to explicitly consider how principals affect attendance, a large literature explores how principals affect student achievement. A broadly accepted conclusion of this literature is that principal effects on student achievement are indirect (e.g., Grissom \& Loeb, 2011; Hallinger \& Heck, 1998; Sebastian \& Allensworth, 2012; Witziers et al., 2003), whereby principals influence school-level factors that in turn affect student learning. In particular, the quality of instruction students receive is the critical in-school factor for their learning. Principals affect this instruction directly through hiring and retention of effective teachers, providing feedback and coaching for existing teachers, and building a strong school climate (Sebastian \& Allensworth, 2012). With respect to student attendance, I argue that while many of these indirect pathways are important, principals' leadership behaviors may also directly influence whether students come to school.

Clearly, teachers remain an indirect channel-prior evidence demonstrated that teachers have large effects on student absences (Gershenson, 2016; Jackson, 2018; Liu \& Loeb, 2019). As primary human capital managers for schools, principals' influence over hiring and retention affects the quality of the school's teaching staff (Cohen-Vogel, 2011; Grissom \& Bartanen, 2019b; Jacob, 2011; Rockoff et al., 2012). Further, the recent studies of teacher effects on non-test score outcomes underscored the multidimensional nature of teacher quality. In short, we know that teachers have differing strengths and that those who contribute most to improving attendance are systematically not those who produce the largest test score gains. Principals, then, can build and maintain a staff of teachers who excel at decreasing student absenteeism. They can also develop staff capacity to engage in effective attendance practices through professional development and coaching of teachers (Attendance Works, 2017).

Beyond influencing the quality of instruction students receive, principals may also directly affect student absences through a number of pathways. ${ }^{3}$ One channel is communication with families. Principals are uniquely positioned to both personally contact parents and coordinate a school-wide policy that increases communication from school staff. Parents of highly truant students often believe that their child's attendance records are average compared to the child's peers (Rogers et al., 2017; Rogers \& Feller, 2018). Relatedly, studies found that informing parents about their child's attendance or the importance of attendance can help improve school attendance rates (e.g., Epstein \& Sheldon, 2002; Robinson et al., 2018; Roderick et al., 1997; Rogers et al., 2017; Smythe-Leistico \& Page, 2018). For example, Robinson et al. (2018) demonstrated in a randomized field experiment that mail-based communication with parents that provided personalized information about their child's absence record and reinforced the importance of regular attendance in grades $\mathrm{K}-5$ lowered chronic absenteeism rates. Even communication with parents not explicitly focused on attendance may be beneficial. Kraft and Rogers (2015) found that in a high school credit recovery program, a randomly assigned intervention delivering weekly individualized text messages to parents about their child's schoolwork decreased the probability of class absence. Similarly, Bergman (2015) found experimental evidence that providing parents with biweekly information about their child's missed assignment and grades lowered absences during the semester.

Principals can also affect student absences through their control over school policies and programs. While empirical evidence in this area is lacking, one focus of states/districts and advocacy groups (e.g., Attendance Works) is to encourage principals to adopt an explicit strategy for reducing absenteeism. As an example, the Connecticut State Department of Education 
maintains a detailed website ${ }^{4}$ that describes the state's vision for reducing chronic absenteeism and provides strategies that principals can implement in their schools. Attendance Works and the National Association of Elementary School Principals published similar guides for school leaders. Beyond outreach to parents and families, common recommendations include implementing or leveraging existing data systems to target supports to students at risk of missing school or establishing procedures for mandatory interventions at a certain absence threshold. Principals can also integrate added supports for improving attendance into school policies that target struggling students, such as response to intervention or positive behavioral interventions and supports (Attendance Works, n.d.). Finally, principals' efforts may also include building relationships that engage local stakeholders, both to draw on outside expertise and increase community awareness of chronic absenteeism as an important issue (Childs \& Grooms, 2018).

To summarize, there are both direct and indirect channels through which principals may affect student absenteeism. While some of these indirect channels are likely the same channels through which principals affect test scores (e.g., human capital management, instructional leadership), principals' frequent interactions with students and families and their unique position to direct school policy are plausibly more direct ways of reducing student absences. While this study cannot identify the relative importance of these pathways, it serves to test the overall magnitude of principals' contributions to student attendance, which helps to lay the groundwork for future research.

\section{Estimating Principal Effects}

To examine the extent to which principal quality matters for student attendance, I draw on value-added modeling. This framework allows me to estimate an "effect" on a given outcome for each individual principal. The distribution of these VA estimates indicates the extent to which variation in principal quality leads to changes in student outcomes. This approach to identifying principal quality is conceptually distinct from a larger body of research that estimated the relationship between principal leadership behaviors and student outcomes (see Liebowitz \& Porter, 2019 , for a review of this research). Here, "quality" is identified not by direct measurement of principals' behaviors or traits but rather the systematic over- or underperformance of their students, adjusting for factors that the principal cannot control.

A handful of prior studies used VA modeling to estimate principal effects on student test scores. ${ }^{5}$ Four studies used large state or district administrative data sets to estimate models with principal and school fixed effects (Branch et al., 2012; Chiang et al., 2016; Dhuey \& Smith, 2018; Grissom et al., 2015). The magnitude of principals' effects ranges between 0.05 and $0.20 S D$-in other words, a $1 S D$ increase in principal quality increases student test scores by 0.05 to $0.20 S D$. Two studies using data from British Columbia-Coelli and Green (2012) and Dhuey and Smith (2014) - found even larger effects, though they used estimation approaches that hinder direct comparison with other studies.

In contrast to the teacher VA literature, little work investigated the validity and reliability of principal VA estimates. The central validity issue is whether the model effectively isolates the "true" contribution of a principal. Neither students nor principals are randomly assigned to schools, which heightens concern that principals are rewarded or punished for factors beyond their control. In particular, prior work highlighted the importance of separating principal effectiveness from school factors such as location or financial resources and demonstrated empirically that school value-added is a poor measure of principal effectiveness (Chiang et al., 2016; Grissom et al., 2015). ${ }^{6}$

The challenge of accounting for school factors is that researchers typically do not observe them or have access to good proxy measures. The solution in the literature is to estimate models with principal and school fixed effects. Intuitively, these models make comparisons among principals who worked in the same school, such that persistent school factors cannot explain differences in student outcomes. This approach, for instance, avoids punishing principals who work in schools that struggle to attract high-quality teachers because of their location. However, including school fixed effects does not eliminate bias from time-varying school factors that the principal cannot control, such as planned facilities upgrades or an increase in community violence. These models also have a considerable practical limitation, which is that most principals can only be compared to small set of other principals.

A second validity concern is the timing of effects. Despite conceptual support for a more dynamic model of principal effects, prior work most often restricted principal quality to be fixed. However, principals' contributions to student outcomes may grow over time (e.g., Coelli \& Green, 2012; Grissom et al., 2015). For instance, a new-to-school principal inherits many of the teachers hired under the old principal. To the extent that human capital management is an important avenue through which principals affect student outcomes (Branch et al., 2012; Grissom \& Bartanen, 2019b; Jacob, 2011), it may take several years for the effect of a high-quality principal to manifest itself through improved student outcomes. Additionally, principals likely improve as they gain experience (Bartanen, 2019; Clark et al., 2009; Grissom et al., 2018), such that producing a single VA estimate for a principal's career masks substantial heterogeneity in their effectiveness over time.

Setting aside the validity issues outlined previously, VA estimates contain both true differences in effectiveness among principals and measurement error. For teacher VA models, reliability is a nontrivial concern due in part to the small number of students per teacher. Principal VA benefits from larger sample sizes because all students in the school contribute to estimation and studies typically pool data across years to produce a single "career VA" estimate. Similar to the approach often implemented in the teacher VA literature, prior studies accounted for measurement error in principal VA using shrinkage estimators (e.g., empirical Bayes), though unsurprisingly, these adjustments tend to be small in magnitude (Branch et al., 2012; Chiang et al., 2016; Grissom et al., 2015).

An overarching theme of the principal effects literature is that while principal VA has largely followed the methodological approach of teacher VA, there are unique challenges to successfully isolating the causal effect of principals on student outcomes. Prior work focused, in particular, on addressing the threat of bias from school factors that the principal cannot control. These studies directly inform my empirical strategy, but I also aim to address 
issues that have yet to receive substantial attention, including the time-varying nature of principal effectiveness.

\section{Data}

This study analyzes administrative data from Tennessee covering the 2006-2007 through 2016-2017 school years, provided by the Tennessee Department of Education via the Tennessee Education Research Alliance. The data contain information about students' enrollment and attendance, including enrollment dates at each school, dates of absences, and a flag for whether the absence was excused or unexcused; the criteria for these designations are determined at the district level. Additionally, I accessed student demographics and the full test score history, which includes end-of-year achievement scores in math and reading for Grades 3 through 8 and end-of-course (EOC) exams for high school students. ${ }^{7}$ I also accessed staff files that allowed me to identify school principals in each year. In total, I observed roughly 3,800 unique principals working in 1,700 schools from 20062007 through 2016-2017.

\section{Operationalizing Student Attendance}

In Tennessee, a student who misses more than $50 \%$ of the school day is recorded as absent. Appendix Figure A1, available on the journal website, shows the distribution of absence rates by grade level for the 2016-2017 school year. Nearly 40\% of students were absent more than $5 \%$ of instructional days, with $13 \%$ reaching the threshold for chronic absenteeism $(10 \%$ absent rate or greater). However, chronic absenteeism was substantially higher in high schools. For example, $26 \%$ of 12 th-grade students were chronically absent, compared to only $13 \%$ of 8 th-grade students and $15 \%$ of 9 th-grade students. Kindergarten students also had high absenteeism rates relative to their older elementary school peers.

I examined four measures of absenteeism. First, I computed each student's total absence rate, which is the number of school days absent divided by the total number of enrolled school days. Additionally, I computed excused and unexcused absence rates by dividing excused/unexcused absences by days enrolled. ${ }^{8}$ Differentiating between excused and unexcused absences is potentially informative given that prior work found that unexcused absences were more detrimental to student learning than excused absences (Gershenson et al., 2017; Gottfried, 2009). Further, the efficacy of principals' efforts could vary between absence types. Finally, I also created a binary indicator for chronic absenteeism, using the standard threshold of $10 \%$ absence rate or above (Jordan et al., 2018). As shown in Appendix Table A3, available on the journal website, the mean absence rate is $5.5 \%$, with a roughly equal split between excused and unexcused absences.

\section{Methods}

\section{Approach 1: Principal and School Fixed Effects}

I begin with the standard approach in the principal effects literature, which includes both principal and school effects. Specifically, I estimated via ordinary least squares the following model:

104

$$
Y_{i s j t}=\alpha Y_{i, t-1}+\beta X_{i t}+\gamma S_{s t}+\pi_{g t}+\delta_{j}+\theta_{s}+\epsilon_{i s j t}
$$

where $i, s, j$, and $t$ index students, schools, principals, and years, respectively; $Y$, a student's absence or achievement outcome, is a function of their prior outcomes (though not necessarily the most recent prior year, as I discuss in the following); a vector of student characteristics, $X$; a vector of school characteristics, $S$; grade-by-year fixed effects, $\pi$; principal fixed effects, $\delta$; school fixed effects, $\theta$; and a random error term, $\epsilon$. Achievement models use students' end-of-year exams for elementary and middle schools and EOC exams for high schools, such that I can estimate both achievement and absence VA across all three school levels. For absence models, the prior-year outcomes include nonparametric functions of a student's prior absence rates and suspensions.?

Given the changing distribution of student absenteeism across grades, I interacted prior absence rates with a student's prior grade to allow for the possibility that the relationship between past and current attendance differs across grade levels. For achievement models, I controlled for cubic functions of prior test scores in math and reading as well as prior-year attendance rates, each interacted with a student's prior grade. ${ }^{10}$ Student characteristics include gender, race/ethnicity, free/ reduced-price lunch eligibility, special education classification, gifted classification, whether the student is repeating the grade, and whether the student has any enrollment spells in another school in the current school year. School characteristics are school-level averages of the student characteristics.

The principal fixed effect, $\delta_{j}$, is the parameter of interest; it captures the extent to which the actual absence rates of students of principal $j$ are higher or lower than what would be predicted by students' prior absences and achievement, individual characteristics, grade, the school year, and school. The model accounts for school quality in two ways: time-varying averages of student demographics and a school fixed effect, $\theta_{s}$. Including school fixed effects accounts for any time-invariant unobserved schoollevel factors. Conceptually, this model identifies principal quality using within-school variation in student outcomes under different principals. The movement of principals across schools creates connected networks of principals, where a principal's estimated effect, $\delta_{j}$, represents their effectiveness relative to other principals in the same network (Burkhauser, 2017; Chiang et al., 2016; Mansfield, 2015).

In practice, principal sorting patterns and high rates of attrition lead to a large number of disconnected networks that often contain only a few principals. The primary limitation of small networks is that principal VA estimates only reflect effectiveness relative to those in the same network rather than across the entire state. Additionally, I could not estimate VA for $17 \%$ of principals because they were the sole principal of a school across the data period. ${ }^{11}$ Removing school fixed effects from the model allows for a global ranking of principals but greatly heightens the possibility of bias from unobserved school heterogeneity. Appendix Table A1, available on the journal website, shows the distribution of networks formed by Tennessee principals based on the analytic sample for estimating absence VA (Appendix Table A2, available on the journal website, shows the networks 
for achievement VA). In sum, the analytic sample included roughly 3,100 principals and 4.3 million student-by-year observations. Descriptive statistics for the analytic sample are shown in Appendix Tables A3 and A4 available on the journal website.

It is important to note that because most students in year $t$ had the same principal in year $t-1$, including prior-year outcomes is a violation of strict exogeneity and potentially biases the principal effect estimates. The degree of this bias likely depends on the nature of how principals affect student outcomes. Controlling for the prior-year outcome is effectively investigating whether a principal causes continued improvement in the outcome, as opposed to a one-time increase. For student achievement, examining continued improvement may be perfectly reasonable. In the case of attendance, however, the inclusion of prior-year outcomes may be more problematic. If, for instance, a new principal implements a program that reduces absenteeism, we might expect to observe a bump in attendance in that year. If absence rates are stable in the following year, we would like to still conclude that the principal was effective at reducing absenteeism. However, if we control for prior-year absences, we will conclude that the principal was not effective at reducing absenteeism in the second year.

One potential solution is to remove the prior-year outcome from the model entirely. However, this heightens the risk of bias from nonrandom student sorting between schools, particularly if students are responding to changes in school quality that are not captured by school fixed effects or demographic controls. I propose a different solution, which is to include in the model the student's most recent prior outcome from their previous school. For example, consider an eighth-grade student who has been in their current school since sixth grade but attended a different school in fifth grade. Instead of controlling for their seventhgrade absences, which are endogenous to both the current principal and school effect (assuming that the principal is not in their first year at the school), I controlled for her fifth-grade absences, which are not affected by the current school or principal. While this approach allowed me to avoid the endogeneity concern, it excluded a nontrivial number of students. Specifically, I could only estimate this model for students that have prior-year outcomes in a different school, which systematically drops students in lower grades and students in the earlier years of the data (see Appendix Table A4 available on the journal website). Fixed effects estimates for elementary school principals thus leverage fewer students (see Appendix Table A5 available on the journal website) and contain more noise.

\section{Approach 2: Drift-Adjusted Value-Added}

A shortcoming of the simple two-way fixed effects approach is that it is inflexible with respect to changes in principal effectiveness over time. My preferred model allowed for changes in performance by producing an effect estimate for each principal-by-year observation. Specifically, I used a modified version of the estimator developed by Chetty et al. (2014) for teacher VA. The estimator had three steps to produce VA for principal $j$ in school $s$ in year $t$ : (a) Residualize students' absences (or achievement) on a vector of observable characteristics (the same student- and schoollevel controls from Equation 1), (b) estimate the best linear predictor of mean absence residuals for all students in school $s$ with principal $j$ in year $t$ based on mean absence residuals for principal $j$ in prior or future years, and (c) use the coefficients of the best linear predictor to predict principal VA in year $t$. In essence, this approach begins by estimating the two-way fixed effects model from Approach 1 but then leverages variation in principal-by-year average residuals to produce a time-varying measure of principal quality. ${ }^{12}$ Appendix B, available on the journal website, contains details on the construction of principal VA using the drift-adjusted estimator. I also performed a validation check proposed by Chetty et al. that tests for forecast bias using students' twice-lagged outcomes (which are omitted from the VA model). Across both absence and achievement outcomes, I found minimal evidence of bias, supporting the claim that the VA estimates are valid measures of principal effectiveness.

There are three important differences between Approaches 1 and 2. First, the VA estimates in Approach 2 (drift-adjusted VA) are leave-year-out measures, meaning that principal-school estimates in year $t$ do not incorporate student outcomes from year $t$. Second, whereas the principal estimates from the fixed effects models in Approach 1 include school-level shocks and student errors (which is the motivation for the empirical Bayes approach), Approach 2 inherently produces shrunken estimates. To the extent that student residuals in a given year are higher or lower due to transitory shocks and/or student-level measurement error (as opposed to the true principal effect), this variation is uncorrelated (in expectation) with residuals in past or future years. Using these past and future residuals to predict contemporaneous residuals, then, will produce an estimate that is shrunken toward the sample mean. Further, this shrinkage also accounts for the number of students that contribute to estimating each principal's effect, such that the adjustment to the estimates for principals in smaller schools will tend to be larger to reflect the fact these estimates are less precise. Finally, the drift-adjusted approach allows for the possibility that principal quality changes over time rather than estimating an average effect across the principal's career.

\section{Results}

\section{Do Principals Affect Student Absences?}

Figure 1 plots the distribution of principal VA estimates from Approaches 1 and 2-the fixed effects and drift-adjusted models-for absence and achievement outcomes, with the corresponding summary statistics shown in Table 1 . The number of principals for whom I could estimate achievement VA was smaller because some schools (e.g., grades $\mathrm{K}-2$ only) did not have end-of-year or EOC exams. The standard deviations of the estimates represent how much principals vary in their effects on student outcomes; a larger standard deviation indicates that principal quality is more consequential for the particular outcome. The units for absence VA are rates (i.e., on a $0 \%-100 \%$ scale), whereas chronic absenteeism VA is expressed in terms of probability. Finally, the units for math and reading achievement are student-level standard deviations.

Studies of principal and teacher effects typically interpret magnitude according the standard deviation of the VA estimates. 


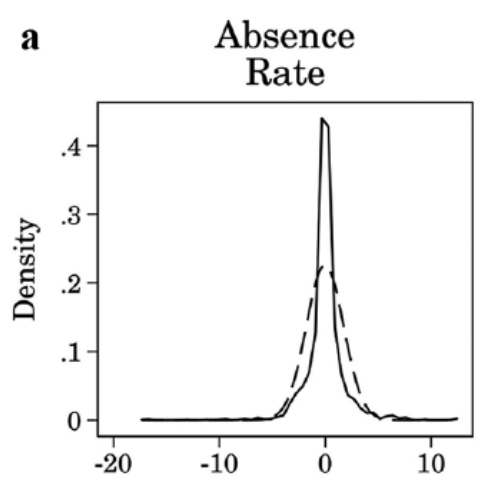

Chronic

Absenteeism

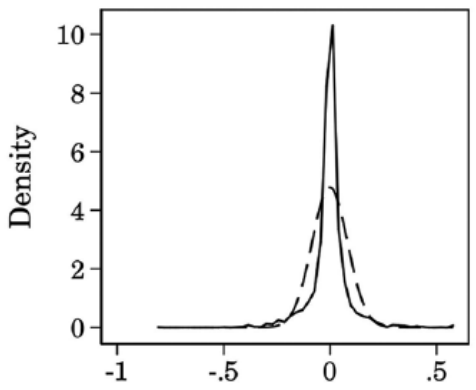

Unexcused

Absence Rate

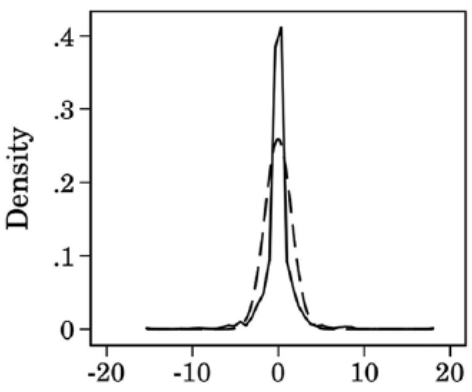

Math

Achievement

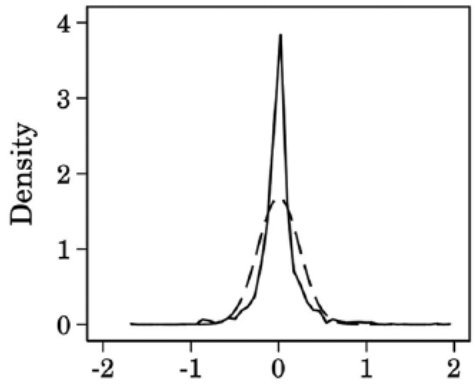

Excused

Absence Rate

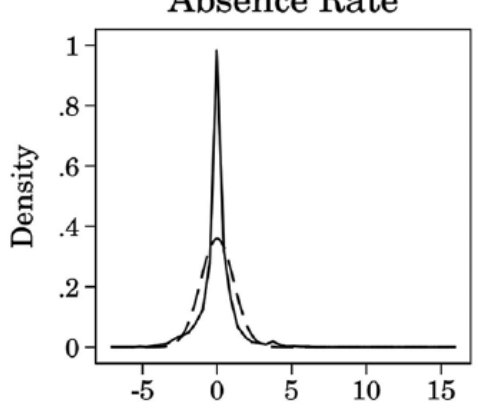

Reading

Achievement

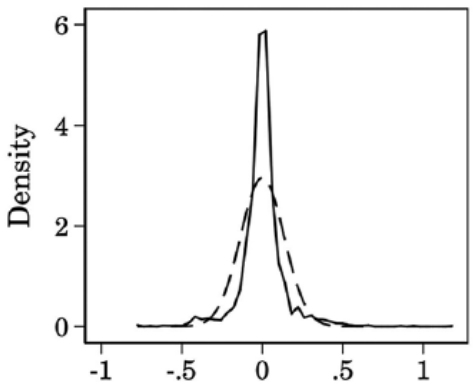

— Value-Added Estimates _ - - Normal Distribution

b

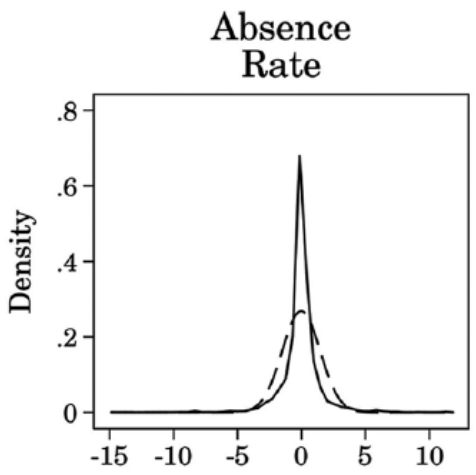

Unexcused

Absence Rate

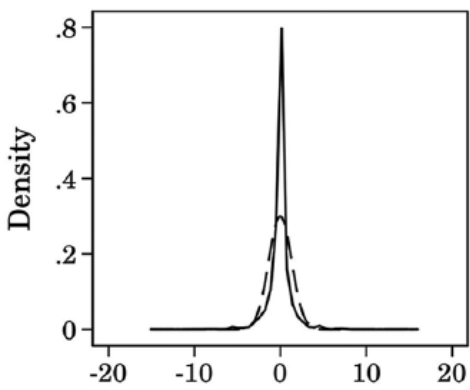

Excused

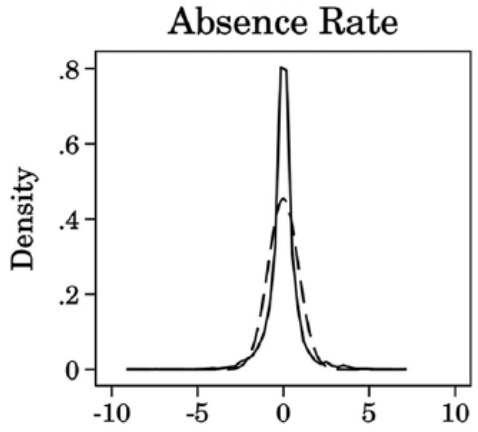

Chronic

Absenteeism

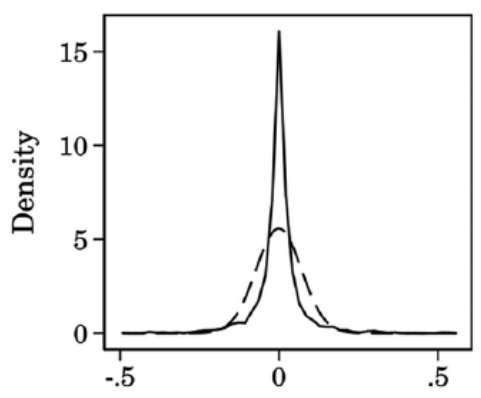

Math

Achievement

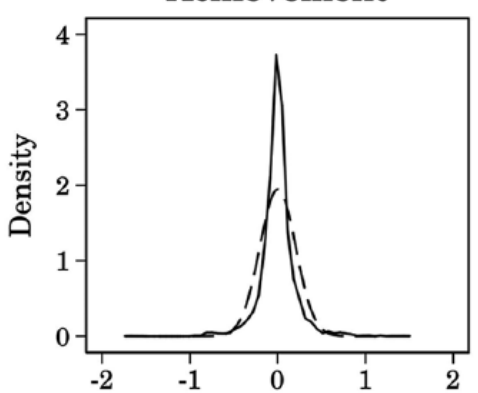

Reading

Achievement

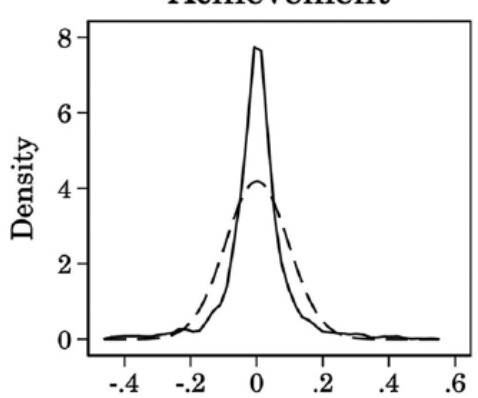

\section{Value-Added Estimates - - - Normal Distribution}

FIGURE 1. Distribution of principal value-added estimates.

Note. (a) Fixed effects. (b) Drift-adjusted. 
This approach makes sense if the estimates are normally distributed. However, the distribution of principal VA estimates is nonnormal (Figure 1). Specifically, the presence of a small number of outliers inflates the standard deviation. To provide a more meaningful interpretation of the magnitude of principal effects on student outcomes, I report the interquartile range (IQR): the difference between the 75th and 25th percentiles in the distribution.

I focus my discussion on the estimates from the driftadjusted approach. I found that principals have substantial effects on student attendance. The IQR of principal VA to absence rates is 0.8 , meaning that replacing a principal at the 25 th percentile with one at the 75 th percentile decreases the absence rate of all students in the school by 0.8 percentage points, on average. This decrease corresponds to 1.4 fewer instructional days missed on a 180-day calendar and 13\% of a standard deviation in absence rates among students in the analytic sample. I also found that principals' effects on attendance operate through both excused and unexcused absences, with only a slightly larger IQR for unexcused absence rates. Finally, I found that moving from the 25 th to 75 th percentile lowers the probability that a student will be chronically absent in the current year by 4 percentage points, or roughly $30 \%$ of the base rate among Tennessee students. ${ }^{13}$

Consistent with prior studies, principals are also an important input to student learning. The IQR of principal VA to math and reading achievement is 0.15 and 0.07 student-level $S D$, respectively. How do principal effects on absences and achievement compare in terms of magnitude? To provide a direct comparison, I reestimated absence VA using rates that are standardized within grade and year (the same process used for test scores). The distribution of these standardized VA estimates are shown in Appendix Table A6, available on the journal website. The IQR of principal VA for total absences, unexcused absences, and excused absences, respectively, is $0.11 S D, 0.12 S D$, and 0.14 $S D$. Thus, the impact of principal quality on student absences is similar in magnitude to the impact on achievement.

\section{Does the Importance of Principal Quality for Student Absences Vary by School Context?}

My second research question examined whether the magnitude of principal effects varied by three categories of school context: school level, school locale, and school poverty (as measured by the percentage of students who qualify for free/reduced-price lunch). Table 2 shows the IQR of the drift-adjusted VA estimates within each of the subgroups of these categories.

The IQR of principal effects on attendance rates is similar across school levels. For instance, the IQR for absence rate VA is 0.9 percentage points among high school principals versus 0.8 for elementary and middle school principals. However, I did find that magnitude of principal effects for achievement outcomes is larger for elementary school principals. ${ }^{14}$ The IQR for math (reading) achievement among elementary school principals is $0.18 S D(0.09 S D)$, compared to $0.14 S D(0.06 S D)$ for middle and high school principals.

For school locale and poverty level, a clear pattern emerged: Principal effects in urban and high-poverty schools are larger across both absence and achievement outcomes. For instance, the IQR for absence rates among principals in urban schools is 1.1 percentage points, compared to 0.8 and 0.7 in suburban and rural schools, respectively. This difference is explained more by unexcused absences, where the magnitude in urban schools (1.1 percentage points) is roughly twice as large as suburban (0.6) and town/rural schools (0.6). I found similarly sized differences for student achievement in math and reading. The largest differences in the magnitudes of principal effects on absences are between high-poverty and low-poverty schools. The IQR for absence rates is twice as large in high-poverty schools (1.4 percentage points) than low-poverty schools ( 0.7 percentage points). Moreover, moving from the 25 th to 75 th percentiles in principal quality lowers the probability of chronic absenteeism by 6 percentage points in high-poverty schools.

In sum, I did find heterogeneity across school contexts in the magnitude of principal effects for both absences and achievement. Principal effects are largest in urban and high-poverty schools - a noteworthy finding given that these schools tend to have students with lower baseline attendance and achievement. Further, prior analysis of the leadership labor market in Tennessee founds that high-poverty and low-achieving schools are the most likely to be led by inexperienced and low-rated principals (Grissom et al., 2019). The findings here further underscore the importance of recruiting and retaining high-quality principals in disadvantaged schools. Finally, while the drivers of absenteeism may be quite different for younger versus older students, principals' contributions to reducing absences are similar in magnitude across school levels. This could suggest that there is not a single pathway through which principals reduce absenteeism but rather, that high-quality principals at different school levels tailor their efforts to address the factors that inhibit attendance for their specific student population.

\section{Comparing Absence VA to Other Measures of Principal Quality}

My final research question investigated whether principals who excel at decreasing student absenteeism can be identified using other measures of principal effectiveness. Specifically, I compared principals' absence VA to their achievement VA as well as high-stakes rubric-based observation scores from their supervisors and low-stakes survey-based ratings from teachers in their school. Table 3 compares principals' estimated VA to absence and achievement outcomes. A natural question is whether principals who increase student achievement also improve attendance. To answer this question, I computed Spearman rank correlations among the VA estimates. However, because the networks used to construct VA estimates for achievement and absences were different, I could not directly compare these estimates. To provide an accurate comparison, I reestimated absence VA using the networks created for achievement VA. It is also important to note that because VA estimates contain measurement error, correlations among these estimates are attenuated. However, applying disattenuation corrections similar to those used in prior studies of teacher VA (e.g., Kraft, 2019) yielded very similar results because the estimated reliability of principal VA estimates is high. ${ }^{15}$ 
Table 1

Distribution of Principal Value-Added Estimates

\begin{tabular}{|c|c|c|c|c|c|c|c|c|}
\hline & $N$ & $S D$ & IQR & \multicolumn{5}{|c|}{ Percentile of Estimates } \\
\hline Absence rate & 3,141 & 1.9 & 1.0 & -1.8 & -0.5 & -0.0 & 0.5 & 1.6 \\
\hline Unexcused absence rate & 3,141 & 1.7 & 0.9 & -1.4 & -0.5 & -0.0 & 0.4 & 1.3 \\
\hline Excused absence rate & 3,141 & 1.2 & 0.8 & -1.2 & -0.4 & 0.0 & 0.4 & 1.2 \\
\hline Math achievement & 2,045 & 0.24 & 0.19 & -0.23 & -0.10 & -0.00 & 0.09 & 0.23 \\
\hline Reading achievement & 2,058 & 0.13 & 0.10 & -0.12 & -0.05 & -0.00 & 0.05 & 0.12 \\
\hline \multicolumn{9}{|l|}{ Drift-adjusted } \\
\hline Absence rate & 13,173 & 1.5 & 0.8 & -1.4 & -0.4 & 0.0 & 0.4 & 1.2 \\
\hline Unexcused absence rate & 13,173 & 1.3 & 0.7 & -1.1 & -0.4 & 0.0 & 0.4 & 1.1 \\
\hline
\end{tabular}

Note. Absence estimates are multiplied by -1 to facilitate comparison with achievement estimates. For absence rates, the scale is $0 \%$ to $100 \%$. Chronic absenteeism is expressed as a probability on a 0 to 1 scale. Achievement outcomes are student-level standard deviation units. Sample sizes for fixed effects are at the principal level, whereas drift-adjusted are at the principal-by-year level. IQR = interquartile range, which is the difference between the 75th and 25th percentiles of the distribution.

Table 2

Interquartile Range of Drift-Adjusted Value-Added Estimates by School Characteristics

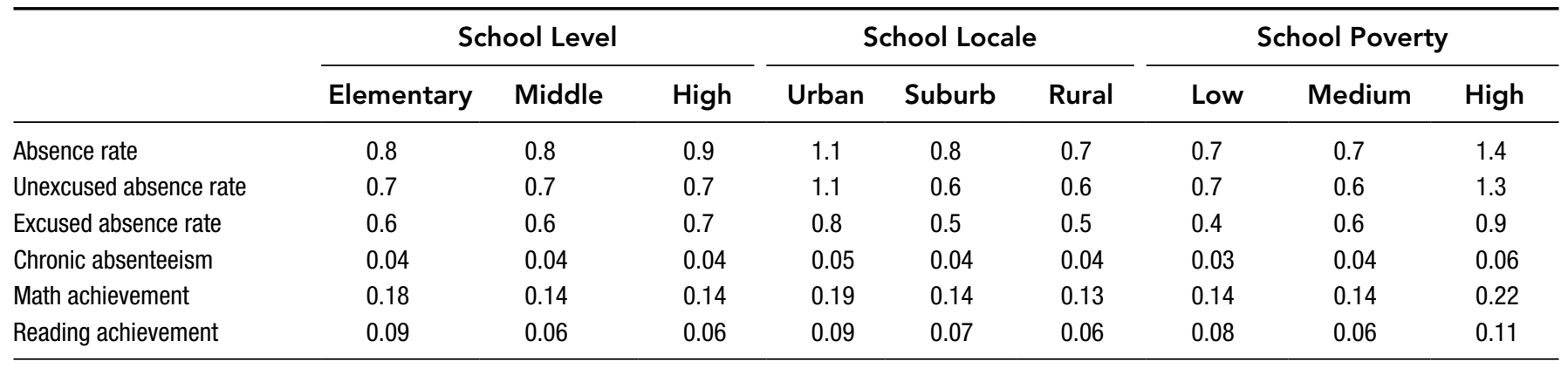

Note. Absence estimates are multiplied by -1 to facilitate comparison with achievement estimates. For absence rates, the scale is $0 \%$ to $100 \%$. Chronic absenteeism is expressed as a probability on a 0 to 1 scale. Achievement outcomes are student-level standard deviation units. School poverty is categorized by the percentage of students in the school who qualify for free/reduced principal lunch: $0 \%$ to $30 \%$ (low), $30 \%$ to $70 \%$ (medium), $70 \%$ to $100 \%$ (high). For school locale, rural includes schools classified as "town" by National Center for Education Statistics.

The first column of Table 3 compares principals' driftadjusted VA across absence and achievement outcomes. ${ }^{16}$ Comparing principals' effects on absences to achievement scores, there are small positive correlations with math and reading VA for each model. For instance, the rank correlation between absence and math (reading) VA is $0.11(0.12)$. In terms of excused versus unexcused absences, the link to achievement is slightly stronger for unexcused absence VA. Table 3 also shows a negative correlation between principal VA for excused and unexcused absences. This likely reflects heterogeneity across principals in terms of setting the criteria for classifying an absence as excused or unexcused. In substantive terms, these modest correlations between absence and achievement VA demonstrate that principals who improve student attendance are not necessarily the same principals whose students have the greatest achievement growth. To the extent that student attendance is an important educational outcome even beyond its relationship with achievement, the results in Table 3 suggest that focusing exclusively on student achievement to identify principal quality will fail to capture the contributions of principals to improving students' noncognitive or character skills, such as attendance.

Table 4 examines correlations between drift-adjusted principal VA estimates and principals' rubric-based ratings from supervisors ${ }^{17}$ and survey-based ratings from teachers. ${ }^{18}$ Specifically, I regressed standardized ratings on standardized principal VA and included fixed effects for each connected network used to construct principal VA and fixed effects for district-by-year.

Columns 1 through 4 in Panel A in Table 4 show no correlation between absence VA and supervisor ratings. In other words, these rubric-based ratings do not contain information about principals' contributions to decreasing student absenteeism. Columns 5 and 6 show the results for achievement VA in math 
Table 3

Spearman Correlations Among Drift-Adjusted Value-Added Estimates

\begin{tabular}{lcccccc}
\hline & Absences & Unexcused Absences & Excused Absences & Chronic Absenteeism & Math & Reading \\
\hline Absence rate & 1.00 & & & & & \\
Unexcused absence rate & 0.63 & 1.00 & 1.00 & & & \\
Excused absence rate & 0.46 & -0.22 & 0.42 & 1.00 & & \\
Chronic absenteeism & 0.91 & 0.58 & 0.02 & 0.09 & 1.00 & 1.00 \\
Math achievement & 0.11 & 0.06 & 0.05 & 0.11 & 0.48 & \\
Reading achievement & 0.12 & 0.07 &
\end{tabular}

Note. Absence estimates are multiplied by -1 to facilitate comparison with achievement estimates.

Table 4

Do Supervisor or Teacher Ratings Identify High Value-Added Principals?

\begin{tabular}{|c|c|c|c|c|c|c|}
\hline & $\begin{array}{c}\text { Absences } \\
\text { (1) }\end{array}$ & $\begin{array}{l}\text { Unexcused Absences } \\
\text { (2) }\end{array}$ & $\begin{array}{c}\text { Excused Absences } \\
\text { (3) }\end{array}$ & $\begin{array}{l}\text { Chronic Absenteeism } \\
\text { (4) }\end{array}$ & $\begin{array}{l}\text { Math } \\
\text { (5) }\end{array}$ & $\begin{array}{c}\text { Reading } \\
\text { (6) }\end{array}$ \\
\hline \multicolumn{7}{|l|}{ Panel A } \\
\hline Supervisor rating & $\begin{array}{c}0.033 \\
(0.035)\end{array}$ & $\begin{array}{c}0.041 \\
(0.037)\end{array}$ & $\begin{array}{c}-0.013 \\
(0.029)\end{array}$ & $\begin{array}{c}0.036 \\
(0.031)\end{array}$ & $\begin{array}{c}0.062 \\
(0.046)\end{array}$ & $\begin{array}{l}0.099^{\star \star \star} \\
(0.036)\end{array}$ \\
\hline$N$ & 7,104 & 7,104 & 7,104 & 7,104 & 4,281 & 4,113 \\
\hline \multicolumn{7}{|l|}{ Panel B } \\
\hline Teacher rating & $\begin{array}{c}0.021 \\
(0.032)\end{array}$ & $\begin{array}{c}0.019 \\
(0.034)\end{array}$ & $\begin{array}{c}0.004 \\
(0.022)\end{array}$ & $\begin{array}{c}0.040^{\star} \\
(0.024)\end{array}$ & $\begin{array}{c}0.032 \\
(0.022)\end{array}$ & $\begin{array}{c}-0.014 \\
(0.023)\end{array}$ \\
\hline$N$ & 6,656 & 6,656 & 6,656 & 6,656 & 4,028 & 3,846 \\
\hline
\end{tabular}

Note. Each cell is a separate regression, where the independent variable is average standardized supervisor rating (Panel A) or average standardized teacher rating (Panel B) and the dependent variable is a principal's standardized VA score from the drift-adjusted approach for the outcome listed in the column header. All models include network and district-by-year fixed effects. Standard errors clustered by principal and network shown in parentheses. Absence value-added estimates are multiplied by -1 to facilitate comparison with achievement estimates. Sample sizes refer to principal-by-year observations beginning in 2011-2012, which is the first year that supervisor and teacher ratings are available.

${ }^{\star} p<.10 .{ }^{* \star *} p<.01$.

and reading. Here, the coefficients are positive and slightly larger in magnitude, though the relationship is only statistically significant at conventional levels for reading. Column 6, for instance, shows that a $1 S D$ increase in a principal's supervisor rating is associated with a $0.10 S D$ increase in their reading VA. Panel B shows the results for teacher ratings. Again, the estimated coefficients are all close to zero, and none are statistically significant at the $95 \%$ level. Overall, the results in Table 4 demonstrate that subjective ratings of performance from supervisors or teachers contain little to no information about principals' contributions to improving student attendance or achievement.

\section{Discussion and Conclusions}

Student attendance is increasingly recognized as an important measure of school success, which has spurred research that examines the extent to which schools affect attendance outcomes. To date, studies almost exclusively focused on teachers, and we have convincing evidence that teachers play an important role in decreasing student absenteeism. However, no studies considered the effect of principals despite strong conceptual reasons to believe that principals can influence absences and prior work demonstrating that principal quality matters for student achievement. I begin to fill this gap by estimating value-added models that isolate the impact of individual principals on student absences. To my knowledge, this study is the first to extend the principal effects literature to a non-test score outcome.

My central finding is that principals have substantive effects on student absences. Moving from the 25 th to 75 th percentiles in principal quality lowers absence rates by 0.8 percentage points, which corresponds to 1.4 additional instructional days for each student in the school, on average. The magnitude of these impacts is roughly comparable to principal effects on test scores. Further, principals have even larger effects in high-poverty and urban schools, which also have the highest rates of chronic absenteeism. Similar to findings from studies that estimated teacher effects on absences, principals who decrease student absences are not necessarily those who increase test scores. Modest correlations between principal VA to absence and achievement outcomes highlight the multidimensional nature of principal quality. In particular, this finding challenges the notion that effective school leadership is completely defined by a principal's ability to drive achievement gains. While there need not be a tradeoff between test score and non-test score outcomes, this study demonstrates that there is still much to be learned about what constitutes principal quality and how to identify effective school leaders.

From a policy perspective, insofar as attendance is an outcome worthy of attention, accountability systems designed around 
identifying principals who increase test scores will fail to identify principals who are improving attendance-and by extension, principals who improve other non-test score outcomes. Indeed, I found that principals' rubric-based scores from supervisors, which comprise half of their summative evaluation rating under Tennessee's high-stakes evaluation system, are not predictive of their contributions to decreasing student absenteeism and are only marginally predictive of principals impacts on student achievement. Given prior research demonstrating a strong relationship between supervisor ratings and principal mobility decisions (Grissom \& Bartanen, 2019a), the findings here suggest that districts may be making placement and retention decisions on the basis of a performance measure that has little connection to student outcomes.

This study is particularly timely given the inclusion of an attendance-related outcome as a measure of school performance in the majority of state accountability plans under the Every Student Succeeds Act. From the perspective of policymakers and district leaders, my results suggest that intervening with principals could be an effective means to address high rates of chronic absenteeism. As states and districts invest additional resources into improving the quality of school leadership, they should consider the multidimensionality of principal effectiveness because the skills and practices that promote test score growth may be different than those that promote regular attendance.

That said, while I document variation in principals' impacts on student absences, an important limitation of this study is that I am unable to identify the specific pathways through which principals influence attendance. Research connecting principals to student outcomes largely focused on test scores, such that the results here highlight the need to expand our thinking about how principals influence other outcomes, especially given increased policy emphasis on understanding and measuring the extent to which schools affect students' noncognitive or socialemotional skills. Future work should aim to identify how principals influence absences or other non-test score outcomes. For instance, how do principals leverage attendance data to identify and support students who are likely to miss school? How do effective principals engage with parents to promote strong attendance habits? Better understanding these mechanisms could provide useful guidance about specific ways to target development opportunities for school leaders to help them lower absenteeism rates.

Additionally, while the methodological choice to use both principal and school fixed effects is important to credibly isolate the contributions of principals from school-level factors they cannot control, it limits the practical use (e.g., for accountability purposes) of these estimates. Even with the population of Tennessee principals across a decade, the majority of principals can only be compared within a small network of connected schools. This practical limitation is not faced by teacher VA models, which typically do not include these school effects and thus can produce a statewide ranking of teachers. ${ }^{19}$ Given the continued emphasis on directly connecting educator evaluation to student outcomes, reconciling the empirical challenges of principal VA and the practical needs of accountability systems is another important avenue for future research. More generally, while I attempt to draw out and address some of the gaps in our understanding of the properties of principal VA estimates, this area remains relatively underdeveloped and worthy of additional attention.

\section{NOTES}

This research was conducted under the auspices of the Tennessee Education Research Alliance, a partnership between the Tennessee Department of Education and Vanderbilt University. I am grateful for feedback and support from my dissertation committee members: Jason Grissom, Dale Ballou, Chris Candelaria, and Kitt Carpenter. I also thank the editor and three anonymous reviewers for their comments and suggestions. Aliza Husain provided helpful feedback on an earlier draft.

${ }^{1}$ The four other indicators are reading and math proficiency, high school graduation rate, English language proficiency, and student test score growth.

${ }^{2}$ Beyond attendance, recent work linked teacher quality to high school graduation (Jackson, 2018; Liu \& Loeb, 2019), students' selfreported attitudes such as motivation and self-efficacy (Blazar \& Kraft, 2017), and complex cognitive skills (e.g., problem solving) and socialemotional competencies (Kraft, 2019).

${ }^{3}$ Here, I use direct to refer to the efforts of principals that are not mostly or completely mediated by teachers or other school staff.

${ }^{4}$ https://portal.ct.gov/SDE/Publications/Reducing-ChronicAbsence-in-Connecticuts-Schools

${ }^{5}$ For sake of simplicity, I also include in this group studies that directly estimated the variance of principal effects but did not estimate effects for individual principals.

'If school factors outside the principal's control are unimportant for student learning, using school value-added (VA) to measure principal performance should produce the same ranking of principals as a model that separates principal and school effects. Both Grissom et al. (2015) and Chiang et al. (2016) showed that these approaches produce very different results.

${ }^{7}$ End-of-course (EOC) exam requirements vary by year. In 20162017, students took exams for Algebra I, geometry, Algebra II, English I, English II, and English III.

${ }^{8}$ Alternative ways of operationalizing absences (e.g., logarithmic transformations, using the raw count data) were very highly correlated with my preferred principal effect estimates.

${ }^{9}$ Specifically, I constructed categorical variables based on the student's prior-year absence rates. For total absences, the categories are as follows: $0 \%, 1 \%$ to $5 \%, 6 \%$ to $10 \%, 11 \%$ to $15 \%, 16 \%$ to $20 \%$, $21 \%$ to $30 \%, 31 \%$ to $40 \%, 41 \%$ to $50 \%, 51 \%$ to $60 \%, 61 \%$ to $70 \%$, $71 \%$ to $80 \%, 81 \%$ to $90 \%, 91 \%$ to $100 \%$. For unexcused and excused absences, the categories are: $0 \%, 1 \%, 2 \%, 3 \%, 4 \%, 5 \%, 6 \%$ to $9 \%$, $10 \%$ to $19 \%, 20 \%$ to $29 \%, 30 \%$ to $39 \%, 40 \%$ to $49 \%, 50 \%$ to $100 \%$. For suspensions, I created separate variables for the number of in-school an out-of-school suspensions the student received: $0,1,2,3+$.

${ }^{10}$ Not controlling for prior-year test scores allowed me to use students from all grades rather than the subset who were in Grades 3 through 8 in the prior year or who took an EOC exam. Including these additional grades increased the network sizes in the two-way fixed effects model and also allowed me to produce estimates for roughly 100 additional principals.

${ }^{11}$ More specifically, I imposed a restriction that all principals in the analytic sample must have at least 50 student-by-year observations. This restriction resulted in dropping a handful of principals who were in networks with one other principal. Since dropping the principal with fewer than 50 observations changed the network to a single principal, the other principal in the network is effectively dropped from the analysis because they no longer have any comparison set. 
${ }^{12}$ One major difference between my approach and the approached used by Chetty et al. (2014) is that I included both school and principal fixed effects in the residualization step. Specifically, Chetty et al. residualized test scores on observable characteristics using within-teacher variation (i.e., with teacher fixed effects). When computing the residuals, they added back in the teacher fixed effects. I performed a similar process with principal effects, with the exception that the residualization included both principal and school fixed effects. When computing the residuals, I added back in the principal fixed effects but not the school fixed effects. As explained previously, this approach accounts for the possibility that the vector of observable characteristics does not fully control for school-level heterogeneity that would otherwise be attributed to principal effectiveness. However, as with Approach 1, employing both principal and school fixed effects means that the VA estimates are only comparable for principals within the same connected network.

${ }^{13}$ One concern is that there are ceiling effects with absences, such that principals in schools with many students with perfect or nearperfect attendance effectively cannot have high value-added because there is no room to improve. While $8 \%$ of Tennessee students have zero absences and $23 \%$ have fewer than three absences, there are relatively few schools that have absence rates close to zero (see Appendix Figure A2, available on the journal website), which suggests that ceiling effects do not substantially affect principals' VA estimates. Prior work investigating ceiling effects in teacher VA also found that even under relatively severe test score ceiling, teachers' VA estimates were negligibly influenced (Koedel \& Betts, 2009). As an additional check, I reestimated the absence VA models under three sample restrictions: dropping students with zero absences, dropping students in the bottom $10 \%$ of the distribution of absence rates, and dropping students in the bottom $25 \%$ of the distribution of absence rates. Appendix Table A8, available on the journal website, shows that the distributions of VA estimates using these restrictions were highly similar to the distribution using the full sample. Additionally, Appendix Table A9, available on the journal website, shows that the rank correlations of principal absence VA were consistently high across these sample restrictions. In sum, these findings suggest that while ceiling effects are present, they likely do not substantially affect principals' VA estimates.

${ }^{14}$ Larger achievement impacts on elementary school students was documented for teacher VA (e.g., Backes \& Hansen, 2018; Chetty et al., 2014).

${ }^{15}$ To explore the plausible magnitude of attenuation in correlations among principal VA estimates, I followed the approach proposed by Kraft (2019), which computed disattenuated Pearson correlations using the Spearman (1904) adjustment. Specifically, the adjustment multiplies the raw correlation by the inverse of the square root of the product of the reliability of the two measures. This disattenuation correction, for instance, increased the Pearson correlation between absence VA and math (reading) VA from $0.13(0.15)$ to $0.15(0.17)$. Full results are available on request.

${ }^{16}$ Appendix Table A7, available on the journal website, shows the correlations for the fixed effects.

${ }^{17}$ These ratings are rubric-based scores that principals receive as part of Tennessee's statewide educator evaluation system (TEAM) implemented in 2011-2012. Fifty percent of the TEAM evaluation for principals comes from ratings of principal performance on a rubric derived from the Tennessee Instructional Leadership Standards. These ratings are based on formal observations conducted by the principal's supervisor. Prior work showed that principals' ratings across indicators were highly interrelated and could be reduced to a single underlying performance score using factor analysis (Grissom et al., 2018). In this analysis, I used principals' average yearly observation scores- the exact measure used by the state to calculate summative evaluation ratings. Using the average observation score instead of the factor score described in Grissom et al. (2018) allowed me to include principals in districts that used alternative observation rubrics (approximately one quarter of principals in the state) given that these districts did not report domainspecific scores for principals. However, for principals for whom I could calculate factor scores, the average observation score and the factor score were correlated at 0.95 or higher each year.

${ }^{18}$ As part of a yearly statewide survey of educators in Tennessee, teachers are asked to provide Likert-scale responses to items that evaluate principal performance. Examples of items include, "The principal at my school communicates a clear vision for this school" and "School leadership makes a sustained effort to address staff concerns." To construct a principal-by-year measure, I factor-analyzed the responses from teachers in each year, averaged the factor scores to the school-by-year level, and standardized the school averages within each year.

${ }^{19}$ Further, even teacher VA models that include both teacher and school effects typically yield a singular connected network because there are many teachers per school and relatively high mobility rates, which produces the variation to connect all of the schools in a state or district (e.g., Mansfield, 2015).

\section{REFERENCES}

Attendance Works. (n.d.). Leading attendance: A toolkit for principals (Tech. Rep.). https://www.attendanceworks.org/wp-content/ uploads/2017/ 09/AW-principal-toolkit-081017-2.pdf

Attendance Works. (2017). Teaching Attendance 2.0: Strategies to help educators infuse attendance into everyday activities (Tech. Rep.). https://www.attendanceworks.org/resources/toolkits/teachingattendance-2-0/teaching-attendance-2-0-introduction/

Aucejo, E. M., \& Romano, T. F. (2016). Assessing the effect of school days and absences on test score performance. Economics of Education Review, 55, 70-87.

Backes, B., \& Hansen, M. (2018). The Impact of Teach For America on non-test academic outcomes. Education Finance and Policy, 13(2), 168-193.

Bartanen, B. (2019). Identifying principal improvement. http:// edworkingpapers.com/ai19-136

Bergman, P. (2015). Parent-child information frictions and human capital investment: Evidence from a field experiment (Tech. Rep.). Center for Economic Studies and Ifo Institute.

Blazar, D., \& Kraft, M. A. (2017). Teacher and teaching effects on students attitudes and behaviors. Educational Evaluation and Policy Analysis, 39(1), 146-170.

Boyd, D., Grossman, P., Ing, M., Lankford, H., Loeb, S., \& Wyckoff, J. (2011). The influence of school administrators on teacher retention decisions. American Educational Research Journal, 48(2), 303-333.

Branch, G. F., Hanushek, E. A., \& Rivkin, S. G. (2012). Estimating the effect of leaders on public sector productivity: The case of school principals. National Bureau of Economic Research.

Burkhauser, S. (2017). How much do school principals matter when it comes to teacher working conditions? Educational Evaluation and Policy Analysis, 39 (1), 126-145.

Cattan, S., Kamhöfer, D. A., Karlsson, M., \& Nilsson, T. (2017). The short-and long-term effects of student absence: evidence from Sweden (Tech. Rep.). IZA Institute of Labor Economics.

Chetty, R., Friedman, J., \& Rockoff, J. (2014). Measuring the impacts of teachers I: Evaluating bias in teacher value-added estimates. American Economic Review, 104(9), 2633-2679.

Chiang, H., Lipscomb, S., \& Gill, B. (2016). Is school value added indicative of principal quality? Education Finance and Policy, 11(3), 283-309.

Childs, J., \& Grooms, A. A. (2018). Improving school attendance through collaboration: A catalyst for community involvement and 
change. Journal of Education for Students Placed at Risk, 23(1-2), 122-138.

Clark, D., Martorell, P., \& Rockoff, J. (2009). School principals and school performance. National Center for Analysis of Longitudinal Data in Education Research.

Coelli, M., \& Green, D. A. (2012). Leadership effects: School principals and student outcomes. Economics of Education Review, 31, 92-109.

Cohen-Vogel, L. (2011). "Staffing to the test": Are today's school personnel practices evidence based? Educational Evaluation and Policy Analysis, 33 (4), 483-505.

Dhuey, E., \& Smith, J. (2014). How important are school principals in the production of student achievement? Canadian Journal of Economics, 47(2), 634-663.

Dhuey, E., \& Smith, J. (2018). How school principals influence student learning. Empirical Economics, 54, 851-882.

Epstein, J. L., \& Sheldon, S. B. (2002). Present and accounted for: Improving student attendance through family and community involvement. Journal of Educational Research, 95(5), 308-318.

Gershenson, S. (2016). Linking teacher quality, student attendance, and student achievement. Education Finance and Policy, 11(2), 125-149.

Gershenson, S., Jacknowitz, A., \& Brannegan, A. (2017). Are student absences worth the worry in U.S. primary schools? Education Finance and Policy, 12(2), 137-165.

Goodman, J. (2014). Flaking out: Student absences and snow days as disruptions of instructional time (Tech. Rep.). National Bureau of Economic Research.

Gottfried, M. A. (2009). Excused versus unexcused: How student absences in elementary school affect academic achievement. Educational Evaluation and Policy Analysis, 31(4), 215-229.

Gottfried, M. A. (2010). Evaluating the relationship between student attendance and achievement in urban elementary and middle schools: An instrumental variables approach. American Educational Research Journal, 47(2), 434-465.

Grissom, J. A., \& Bartanen, B. (2019a). Principal effectiveness and principal turnover. Education Finance and Policy, 14(3), 355-382.

Grissom, J. A., \& Bartanen, B. (2019b). Strategic retention: Principal effectiveness and teacher turnover in multiple-measure teacher evaluation systems. American Educational Research Journal, 56 (2), 514-555.

Grissom, J. A., Bartanen, B., \& Mitani, H. (2019). Principal sorting and the distribution of principal quality. AERA Open, 5(2), $1-21$.

Grissom, J. A., Blissett, R. S. L., \& Mitani, H. (2018). Evaluating school principals: Supervisor ratings of principal practice and principal job performance. Educational Evaluation and Policy Analysis, 40(3), 446-472.

Grissom, J. A., Kalogrides, D., \& Loeb, S. (2015). Using student test scores to measure principal performance. Educational Evaluation and Policy Analysis, 37 (1), 3-28.

Grissom, J. A., \& Loeb, S. (2011). Triangulating principal effectiveness: How perspectives of parents, teachers, and assistant principals identify the central importance of managerial skills. American Educational Research Journal, 48(5), 1091-1123.

Hallfors, D., Vevea, J. L., Iritani, B., Cho, H., Khatapoush, S., \& Saxe, L. (2002). Truancy, grade point average, and sexual activity: A metaanalysis of risk indicators for youth substance use. Journal of School Health, 72(5), 205-211.

Hallinger, P., \& Heck, R. H. (1998). Exploring the principal's contribution to school effectiveness: 1980-1995. School Effectiveness and School Improvement, 9(2), 157-191.
Heckman, J., \& Kautz, T. (2013). Fostering and measuring skills: Interventions that improve character and cognition. National Bureau of Economic Research.

Henry, K. L., \& Thornberry, T. P. (2010). Truancy and escalation of substance use during adolescence. Journal of Studies on Alcohol and Drugs, 71 (1), 115-124.

Jackson, C. K. (2018). What do test scores miss? The importance of teacher effects on non-test score outcomes. Journal of Political Economy, 126(5), 699018.

Jacob, B. (2011). Do principals fire the worst teachers? Educational Evaluation and Policy Analysis, 33(4), 403-434.

Jordan, P. W., Fothergill, S., \& Rosende, M. (2018). Writing the rules: Ensuring chronic absenteeism data works for schools and students (Tech. Rep.). FutureEd.

Jordan, P. W., \& Miller, R. (2017). Who's in: Chronic absenteeism under the Every Student Succeeds Act (Tech. Rep.). FutureEd.

Koedel, C., \& Betts, J. (2009). Value added to what? How a ceiling in the testing instrument influences value-added estimation. Education Finance and Policy, 5 (1), 54-81.

Kraft, M. A. (2019). Teacher effects on complex cognitive skills and socialemotional competencies. Journal of Human Resources, 54(1), 1-36.

Kraft, M. A., Marinell, W. H., \& Yee, D. (2016). School organizational contexts, teacher turnover, and student achievement: Evidence from panel data. American Educational Research Journal, 53(5), 1411-1449.

Kraft, M. A., \& Rogers, T. (2015). The underutilized potential of teacher-to-parent communication: Evidence from a field experiment. Economics of Education Review, 47, 49-63.

Ladd, H. F. (2011). Teachers' perceptions of their working conditions: How predictive of planned and actual teacher movement? Educational Evaluation and Policy Analysis, 33(2), 235-261.

Liebowitz, D. D., \& Porter, L. (2019). The effect of principal behaviors on student, teacher, and school outcomes: A systematic review and meta-analysis of the empirical literature. Review of Educational Research, 89(5), 785-827.

Liu, J., Lee, M., \& Gershenson, S. (2019). The short- and long-run impacts of secondary school absences. http://www.edworkingpapers .com/ai19-125

Liu, J., \& Loeb, S. (2019). Engaging teachers: Measuring the impact of teachers on student attendance in secondary school. Journal of Human Resources. Advance online publication. http://jhr.uwpress .org/content/early/2019/07/02/jhr.56.2.1216-8430R3

Mansfield, R. K. (2015). Teacher quality and student inequality. Journal of Labor Economics, 33(3), 751-788.

Robinson, C. D., Lee, M. G., Dearing, E., \& Rogers, T. (2018). Reducing student absenteeism in the early grades by targeting parental beliefs. American Educational Research Journal, 55(6), 1163-1192.

Rockoff, J. E., Staiger, D. O., Kane, T. J., \& Taylor, E. S. (2012). Information and employee evaluation: evidence from a randomized intervention in public schools. The American Economic Review, 102(7), 3184-3213.

Roderick, M., Arney, M., Axelman, M., Dacosta, K., Steiger, C., Stone, S., Villarreal-Sosa, L., \& Waxman, E. (1997). Habits hard to break: A new look at truancy in Chicago's public high schools (Tech. Rep.). School of Social Service Administration, University of Chicago.

Rogers, T., Duncan, T., Wolford, T., Ternovski, J., Subramanyam, S., \& Reitano, A. (2017). A randomized experiment using absenteeism information to 'nudge' attendance (Tech. Rep.). U.S. Department of Education, Institute of Education Sciences, National Center for Education Evaluation and Regional Assistance, Regional Education Laboratory Mid-Atlantic.

Rogers, T., \& Feller, A. (2018). Reducing student absences at scale by targeting parents' misbeliefs. Nature Human Behaviour, 2(5), $335-342$. 
Sebastian, J., \& Allensworth, E. (2012). The influence of principal leadership on classroom instruction and student learning: A study of mediated pathways to learning. Educational Administration Quarterly, 48(4), 626-663.

Smythe-Leistico, K., \& Page, L. C. (2018). Connect-text: Leveraging text-message communication to mitigate chronic absenteeism and improve parental engagement in the earliest years of schooling. Journal of Education for Students Placed at Risk, 23(1-2), 139-152.

Spearman, C. (1904). The proof and measurement of association between two things. The American Journal of Psychology, 15(1), 72-101.

Witziers, B., Bosker, R. J., \& Krüger, M. L. (2003). Educational leadership and student achievement: The elusive search for an association. Educational Administration Quarterly, 39(3), 398-425.

\section{AUTHOR}

BRENDAN BARTANEN, PhD, is an assistant professor in the Department of Educational Administration and Human Resource Development at Texas A\&M University, 527 Harrington Tower, 4226 TAMU, College Station, TX 77843; bartanen@tamu.edu. His research interests include educator labor markets, principal quality, and evaluation systems.

Manuscript received June 3, 2019

Revisions received August 15, 2019, and October 10, 2019

Accepted October 20, 2019 